\title{
BMJ Open Enduring health effects of asbestos use in Belgian industries: a record-linked cohort study of cause-specific mortality (2001-2009)
}

\author{
Laura Van den Borre, Patrick Deboosere
}

To cite: Van den Borre L, Deboosere P. Enduring health effects of asbestos use in Belgian industries: a recordlinked cohort study of causespecific mortality (20012009). BMJ Open 2015;5: e007384. doi:10.1136/ bmjopen-2014-007384

- Prepublication history for this paper is available online. To view these files please visit the journal online (http://dx.doi.org/10.1136/ bmjopen-2014-007384).

Received 5 December 2014 Revised 24 February 2015 Accepted 20 March 2015

CrossMark

Interface Demography, Department of Sociology, Vrije Universiteit Brussel, Brussels, Belgium

\section{Correspondence to} Laura Van den Borre; Laura.Van.den.Borre@vub. ac.be

\section{ABSTRACT}

Objective: To investigate cause-specific mortality among asbestos workers and potentially exposed workers in Belgium and evaluate potential excess in mortality due to established and suspected asbestosrelated diseases.

Design: This cohort study is based on an individual record linkage between the 1991 Belgian census and cause-specific mortality information for Flanders and Brussels (2001-2009).

Setting: Belgium (Flanders and Brussels region). Participants: The study population consists of 1397699 male workers (18-65 years) with 72074 deaths between 1 October 2001 and 31 December 2009. Using a classification of high-risk industries, mortality patterns between 2056 asbestos workers, 385046 potentially exposed workers and the working population have been compared.

Outcome measures: Standardised mortality ratios (SMRs) and $95 \% \mathrm{Cls}$ are calculated for manual and nonmanual workers.

Results: Our findings show clear excess in asbestosrelated mortality in the asbestos industry with SMRs for mesothelioma of 4071 (Cl 2327 to 6611) among manual workers and of 4489 (Cl 1458 to 10476 ) among nonmanual workers. Excess risks in asbestos-related mortality are also found in the chemical industry, the construction industry, the electrical generation and distribution industry, the basic metals manufacturing industry, the metal products manufacturing industry, the railroad industry, and the shipping industry. Oral cancer mortality is significantly higher for asbestos workers (SMR 383; Cl 124 to 894), railroad workers (SMR 192; Cl 112 to 308), shipping workers (SMR 172; Cl 102 to 271) and construction workers (SMR 125; $\mathrm{Cl} 100$ to 153), indicating a possible association with occupational asbestos exposure. Workers in all four industries have elevated mortality rates for cancer of the mouth. Only construction workers experience significantly higher pharyngeal cancer mortality (SMR 151; Cl 104 to 212).

Conclusions: The study identifies vulnerable groups of Belgian asbestos workers, demonstrating the current-day health repercussions of historical asbestos use. Results support the hypothesis of a possible association between the development of oral cancer and occupational asbestos exposure.

\section{Strengths and limitations of this study}

- Mortality among Belgian workers is investigated using exhaustive census-linked cause-specific mortality data at the individual level.

- The availability of a large national database allows the study of industries with a relatively small number of workers.

- Asbestos exposure data is not available for Belgium and could not be included in this study. However, high-risk industries are selected based on an extensive literature review and the strong aetiological relation between mesothelioma and asbestos exposure. A further differentiation is made between manual and non-manual workers.

- Occupational information is only available for one point in time. Workers exposed before the census date may have been included in the reference population (eg, job change) or may have left the active population (eg, health reasons). Potential confounders after the census date are not taken into account. Our results may underestimate the true influence of occupational asbestos exposure.

\section{INTRODUCTION}

Belgium has the fourth highest mesothelioma mortality rate in the world, after the UK, Australia and Italy. Since 2006, over 200 Belgians have died from mesothelioma each year. ${ }^{1}$ Mesothelioma is considered to be a potent and sensitive indicator of asbestos exposure, ${ }^{2}$ but further research on other asbestos-related diseases is imperative to understand the full extent of the asbestos problem in Belgium. This study focuses on the primary source of asbestos exposure: the workplace.

Asbestos minerals do not occur naturally in Belgium. With the start of one of Europe's largest asbestos companies, Eternit, in the early 1900s, Belgium rapidly became an important supplier of asbestos products. Large amounts of raw asbestos fibres were 
imported for manufacturing purposes since the 1930s. ${ }^{3}$ Belgian asbestos industries used a mix of different types of asbestos, usually consisting of $90-99 \%$ chrysotile and $10-1 \%$ crocidolite. ${ }^{4}$ The use of relatively small amounts of amosite has also been reported. ${ }^{5}$

Asbestos use culminated during the 1960s-1970s, with Belgium having the highest asbestos consumption level per capita in the world. ${ }^{6}$ Since then, overall exposure levels have gradually decreased as a result of private and public health control measures, including the mandatory use of dust masks and the installation of exhaust systems in the workplace. ${ }^{7}$ Airborne occupational exposure limits for asbestos were implemented in 1980 to control exposure intensity and duration. ${ }^{8}$ Nonetheless, these measures did not avert all fatal health effects due to asbestos exposure.

Despite declining asbestos exposure levels, occupational exposure in, for example, asbestos product manufacturing, shipbuilding and construction, remained relatively common until the end of the 1990s. Industrial asbestos use was reduced dramatically with a major ban on all asbestos types in 1998. Some exceptions for chrysotile products remained until 2001, when the use and transaction of all types of asbestos were finally banned.

The few Belgian studies on asbestos health risks in the workplace are based on industry findings, biomedical data or information delivered by victim compensation

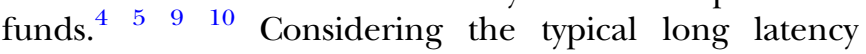
periods of asbestos-related diseases and most occupational asbestos research dating back to the 1960s-1970s, results may not reflect the true public health consequences of industrial asbestos use. Selection bias, differences in diagnostic criteria and low civil awareness of compensation measures, make the representativeness of these data sources questionable.

International studies on the health of asbestos workers focus mainly on well-established asbestos-related diseases, namely asbestosis, malignant mesothelioma and lung cancer. Recently, the International Agency for Research on Cancer has acknowledged a causal effect in the development of laryngeal and ovarian cancer. ${ }^{11}$ The association between asbestos exposure and several other malignancies remains controversial.

The present study investigates cause-specific mortality among asbestos workers and potentially exposed workers to evaluate potential excess in mortality due to established and suspected asbestos-related diseases. For the first time, mortality follow-up data and individual employment information for a large study population are available to determine the impact of asbestos exposure on Belgian male workers.

\section{METHODS}

Study design

An anonymous record linkage has been performed between detailed occupational information from the
1991 Belgian census and cause-specific mortality data from 1 October 2001 to 31 December 2009. The record linkage was based on a primary link between the 1991 Belgian census, and registration records of all deaths and migrations between the census date (1 March 1991) and 31 December 2009. Then, cause-specific mortality information was derived from death certificates for the period 2001-2009 and added to the dataset. As a result, there is a 10-year time lag between occupational information and cause-specific mortality data.

Death certificates are not available for the 3 Belgian regions. The cause-specific mortality data only covers Flanders and the Brussels Capital Region, where the majority of Belgian asbestos firms were located. ${ }^{1}$ According to data from the Scientific Institute for Public Health, all-cause mortality in Flanders and Brussels accounts for $65 \%$ of all Belgian male deaths in 20032010. Approximately $80 \%$ of all male mesothelioma mortality occurs among Flemish and Brussels men. ${ }^{12}$

Based on the 1991 census, we have identified 1537805 occupationally active men (18-65 years) in Flanders and the Brussels Capital Region. Prior to 1 October 2001, 3.5\% of these workers emigrated and $3.6 \%$ died. Owing to missing occupational information, 30922 workers could not be classified.

The study investigates 72074 deaths between 1 October 2001 and 31 December 2009, among a cohort of 1397699 Flemish and Brussels men with valid occupational information at the time of the 1991 census.

\section{Classification of high-risk industries}

The comprehensive character of the census data provides a snapshot of the occupational distribution. Consequently, the risks of persons who have been at least potentially exposed to asbestos can be compared with all other occupational groups. Information about exposure circumstances is not available. Because of the widespread use of asbestos fibres in Belgium, careful consideration is required to distinguish occupational asbestos exposure from environmental or secondary exposure. We have combined the distribution of mesothelioma deaths in Belgian industries with an extensive literature review to determine the industries most at risk of asbestos-related health effects.

Malignant mesothelioma mortality was used as a marker for asbestos exposure (Tenth Revision of the International Classification of Diseases, ICD-10 C45). This highly fatal cancer develops in the protective linings of the lungs, chest wall, abdomen and heart, and is caused almost exclusively by asbestos exposure. Even low levels of asbestos exposure can induce malignant mesothelioma. ${ }^{13}$ Industrial sectors with at least three mesothelioma deaths during the period 2001-2009 were selected using the Statistical Classification of Economic Activities in the European Community (NACE).

We have cross-referenced these findings with the published literature. An extensive review of international and national studies on occupational asbestos exposure 
was conducted to ascertain at least potential asbestos use in these industries. Databases PubMed and Unicat (Union Catalogue of Belgian Libraries) have been examined. Keywords included "occupation*", "industr*", "asbestos", "health", "mortality", "Belg*". Additional searches were conducted using the names of the selected industries. Only peer-reviewed articles and government documents were considered. We have made no restrictions in time or language. If industrial asbestos use was established in at least one of the studies, the industry was included in further analyses.

Finally, industries with at least three mesothelioma deaths in the period 2001-2009 and with conclusive evidence of asbestos use were considered as high-risk industries. Three broad categories can be distinguished. Table 1 presents detailed information on the activities of the analysed industries in each category. Category A includes workers in asbestos industries. Category B includes workers in industries with potential asbestos exposure. Category $\mathrm{C}$ consists of workers in all industries excluded from categories A or B.

A further differentiation was made between manual workers and all other occupational types in high-risk industries. The 1991 census includes information on the type of performed labour: self-employed, blue-collar, white-collar, management, etc. We defined manual workers as blue-collar workers and self-employed persons. ${ }^{i}$

Table 2 provides an overview of the number of manual and non-manual workers per industry, together with allcause mortality and mesothelioma mortality. Of 704458 manual workers in 1991, 40\% were active in high-risk industries. All other occupational types in these industries account for approximately 15\% of all 693241 nonmanual workers.

It is important to bear in mind an undetermined level of asbestos exposure for all categories of workers. Questions on occupational history are not included in the 1991 census. Hence, this research design cannot consider exposure duration or exposure in previous workplaces. In addition, workers may have been exposed to asbestos via the environment or through indirect contact.

\section{Data analysis}

Analyses are performed separately for manual and nonmanual workers. Standardised mortality rates (SMRs) are calculated by 5-year age group with reference to workers in all other industries (category $\mathrm{C}$ ). Lower and upper $95 \%$ CI are computed assuming that the observed deaths are Poisson variates. If the observed number of deaths is less than 100, exact limits are calculated directly from the Poisson distribution. For larger numbers, we use the Byar approximation method. ${ }^{14}$

${ }^{\text {i }}$ Self-employed persons constitute a small, but relevant, population in the construction industry ( $9 \%$ of manual workers), automotive industry (5\% of manual workers; mainly in repair and maintenance work) and metal products manufacturing (3\% of manual workers).
Data for the study period 2001-2009 are combined because of the small number of cases per year for some of the industries under investigation. Analyses are based on the underlying cause of death as recorded on the death certificate. Cause-specific mortality is coded using the ICD-10.

\section{RESULTS}

A total of 996 men died due to mesothelioma from 2001 through 2009. Although previous occupational asbestos exposure is possible, 545 mesothelioma deaths in the non-active population have been discarded from the classification process. One hundred and ninety-four deaths occurred among 173137 men past the retirement age of 65 years in 1991, and 351 deaths occurred among 510681 non-active men aged 18-65 years. The selection of high-risk industries is based on a total of 439 mesothelioma deaths in the active population $(\mathrm{n}=1397699)$.

Table 3 compares mesothelioma and all-cause mortality in the active and non-active population for men at working ages in 1991. From 2001 to 2009, 21 asbestos workers and 169 potentially exposed workers died due to mesothelioma. Two hundred and forty-nine mesothelioma deaths occurred in the reference population. The high overall mortality among non-active men before age 65 years indicates a "healthy worker effect". Healthy workers remain in the workforce whereas persons with health problems are more inclined to quit prematurely. We restrict further analysis to the active population in 1991.

The results on asbestos-related mortality among asbestos workers and potentially exposed workers are presented in table 4, with the SMRs and $95 \%$ CIs by occupational type for the period 2001-2009.

\section{Asbestos-related mortality \\ Asbestos workers}

Mesothelioma mortality is over 40 times higher among manual workers in the asbestos industry than among all other workers (SMR 4071; CI 2327 to 6611). Manual workers also experience $75 \%$ more lung cancer deaths than expected (SMR 175; CI 108 to 268). Results on laryngeal cancer mortality are inconclusive, as the ratio is based on only one observed death. No asbestosis deaths occurred among manual workers during the period 2001-2009.

We also find significant excess in asbestos-related mortality for jobs that do not involve direct contact with asbestos fibres. Non-manual workers in the asbestos industry have 45 times higher mesothelioma mortality than expected (SMR 4489; CI 1458 to 10 476). Laryngeal cancer mortality is almost 15 times higher than expected (SMR 1425; CI 173 to 5148). Contrary to their colleagues in manual labour jobs, non-manual workers do not seem to experience higher lung cancer mortality (SMR 29; CI 1 to 161). 
Table 1 Types of industrial activities, per category

\begin{tabular}{|c|c|}
\hline Industry & Industrial activity \\
\hline \multicolumn{2}{|l|}{$(A)$} \\
\hline Asbestos industry & $\begin{array}{l}\text { Asbestos cement manufacturing } \\
\text { Asbestos products manufacturing }\end{array}$ \\
\hline \multicolumn{2}{|l|}{ (B) } \\
\hline Automotive industry & $\begin{array}{l}\text { Manufacture and assembly of car parts } \\
\text { Manufacture and assembly of motor cycle parts } \\
\text { Repair and maintenance }\end{array}$ \\
\hline Chemical industry & $\begin{array}{l}\text { Manufacture of basic chemicals } \\
\text { Manufacture of pesticides and other agrochemical products } \\
\text { Manufacture of paints and similar coatings } \\
\text { Manufacture of soap, cosmetics and detergents } \\
\text { Manufacture of other chemical products } \\
\text { Manufacture of man-made fibres } \\
\text { Manufacture of basic pharmaceutical products }\end{array}$ \\
\hline Construction & $\begin{array}{l}\text { General construction and demolition } \\
\text { Construction of buildings and utilities } \\
\text { Civil engineering: roads and water supply } \\
\text { Installation companies } \\
\text { Final construction work }\end{array}$ \\
\hline Electricity generation and distribution & Electricity generation and distribution \\
\hline Electrotechnical products manufacturing & $\begin{array}{l}\text { Manufacture of electrical appliances } \\
\text { Assembly and installation of electrotechnical products }\end{array}$ \\
\hline Manufacture of basic metals & $\begin{array}{l}\text { Manufacture of basic iron, steel and ferroalloys } \\
\text { Manufacture of steel tubes, pipes and related fitting } \\
\text { Manufacture of other products of first processing of steel } \\
\text { Manufacture of basic non-ferrous metals }\end{array}$ \\
\hline Metal products manufacturing & $\begin{array}{l}\text { Casting of metal } \\
\text { Manufacture of fabricated metal products } \\
\text { Manufacture and assembly structural metal parts } \\
\text { Manufacture of boilers and reservoirs } \\
\text { Grinderies and other }\end{array}$ \\
\hline Railroad industry & $\begin{array}{l}\text { Railway carriage construction } \\
\text { Repair and maintenance } \\
\text { Activities related to railway transport }\end{array}$ \\
\hline Shipping industry & $\begin{array}{l}\text { Shipyards, ship repair and maintenance } \\
\text { Activities related to inland, maritime and short sea shipping }\end{array}$ \\
\hline Textile industry & $\begin{array}{l}\text { Wool, cotton and other } \\
\text { Carpet, felt and linoleum } \\
\text { Other activities }\end{array}$ \\
\hline
\end{tabular}

(C)

All other workers

\section{Potentially exposed workers}

Workers from the automotive industry, the electrical products manufacturing industry and the textile industry do not seem to experience significant excess in mortality due to asbestos-related diseases (not shown in table 4).

Mesothelioma mortality is significantly higher among manual workers in the electrical generation and distribution industry (SMR 863; CI 317 to 1878), shipping industry (SMR 475; CI 266 to 784), railroad industry (SMR 352; CI 141 to 725), chemical industry (SMR 293; CI 160 to 492), basic metals manufacturing industry (SMR 291; CI 145 to 520) and the construction industry (SMR 227; CI 168 to 302). Manual workers in the metal products manufacturing industry have a SMR of 187 (CI 85 to 354 ).
Lung cancer deaths are significantly higher than expected among construction workers (SMR 153; CI 144 to 163), shipping workers (SMR 141; CI 119 to 167) and metal products manufacturing workers (SMR 138; CI 119 to 158 ) in manual labour jobs.

With regard to laryngeal cancer mortality, observed deaths among manual workers in the construction industry are twice as high as expected (SMR 203; CI 155 to 260$)$.

Among all potentially exposed workers in manual labour, four cases of asbestosis deaths have been recorded. Three deaths occurred among construction workers, resulting in an elevated SMR for asbestosis (SMR 401; CI 83 to 1171). One worker in metal products manufacturing died due to asbestosis. 
Table 2 Mesothelioma deaths and total number of deaths for manual and non-manual workers by industry

\begin{tabular}{|c|c|c|c|c|c|c|c|c|c|}
\hline \multirow[b]{2}{*}{ Industry } & \multicolumn{3}{|c|}{ Manual workers } & \multicolumn{3}{|c|}{$\begin{array}{l}\text { Non-manual } \\
\text { workers }\end{array}$} & \multicolumn{3}{|l|}{ Total } \\
\hline & $\overline{\mathbf{N}}$ & $\mathbf{M}$ & D & $\overline{\mathbf{N}}$ & $\mathbf{M}$ & D & $\overline{\mathbf{N}}$ & $\mathbf{M}$ & D \\
\hline \multicolumn{10}{|l|}{$(A)$} \\
\hline $\begin{array}{l}\text { Asbestos industry } \\
\text { (B) }\end{array}$ & 1743 & 16 & 121 & 313 & 5 & 18 & 2056 & 21 & 139 \\
\hline Automotive industry & 52789 & 8 & 1856 & 12057 & 1 & 261 & 64846 & 9 & 2417 \\
\hline Chemical industry & 21875 & 14 & 957 & 18647 & 4 & 882 & 40522 & 18 & 1839 \\
\hline Construction industry & 100297 & 48 & 5341 & 22387 & 16 & 1333 & 122684 & 64 & 6674 \\
\hline Electricity generation and distribution & 2164 & 6 & 133 & 4489 & 7 & 277 & 6653 & 13 & 410 \\
\hline Electrotechnical products manufacturing & 15854 & 3 & 571 & 12920 & 6 & 462 & 28774 & 9 & 1033 \\
\hline Manufacture of basic metals & 17174 & 11 & 748 & 5209 & 3 & 263 & 22383 & 14 & 1011 \\
\hline Metal products manufacturing & 29960 & 9 & 1211 & 6603 & 2 & 298 & 36563 & 11 & 1509 \\
\hline Railroad industry & 10840 & 7 & 467 & 12352 & 3 & 547 & 23192 & 10 & 1014 \\
\hline Shipping industry & 12255 & 15 & 784 & 3380 & 1 & 204 & 15635 & 16 & 988 \\
\hline Textile industry & 20008 & 3 & 1043 & 3786 & 2 & 159 & 23794 & 5 & 1202 \\
\hline \multicolumn{10}{|l|}{ (C) } \\
\hline Reference population & - & - & - & - & - & - & 1010597 & 249 & 53838 \\
\hline
\end{tabular}

The results for non-manual workers show significant excess in asbestos-related mortality in two industries with potential asbestos exposure. We find significant excess in mesothelioma mortality and asbestosis mortality in the construction industry with SMRs of 260 (CI 149 to 422) and 843 (CI 102 to 3043), respectively. Mesothelioma mortality is more than four times higher among nonmanual workers in the electricity generation and distribution industry (SMR 430; CI 173 to 885).

Electricity generation and distribution is also one of three industries with a significant deficit in lung cancer mortality for non-manual workers (SMR 66; CI 46 to 93). The SMRs for lung cancer in the chemical industry and the basic metal manufacturing industry are 67 (CI 55 to 81 ) and 57 (CI 38 to 82), respectively.

\section{Other causes of death}

Table 5 presents the number of deaths from other causes by industry and occupational type, with the corresponding SMRs and 95\% CIs. Results indicate significantly more oral cancer deaths among manual workers in the asbestos industry, railroad industry, shipping industry and the construction industry. When examining more closely, high oral cancer mortality is driven by excess deaths due to cancers of the mouth (ICD-10 C01-C06) in all four industries. Mouth cancer mortality is nine times higher among asbestos workers (SMR 938; CI 305 to 2189). Railroad workers experience about four times more mouth cancer deaths (SMR 390; CI 213 to 655). Shipping workers have an elevated SMR of 211 (CI 96 to 400$)$. Construction workers experience $40 \%$ more

Table 3 Mesothelioma and all-cause mortality in 2001-2009 by activity status for men aged 18-65 years in 1991*

\begin{tabular}{|c|c|c|c|c|c|}
\hline \multirow[b]{2}{*}{ Characteristics } & \multirow[b]{2}{*}{$\mathbf{N}$} & \multicolumn{2}{|c|}{ Mesothelioma } & \multicolumn{2}{|l|}{ Overall } \\
\hline & & $\overline{0}$ & SMR (Cl) & $\mathbf{0}$ & SMR (Cl) \\
\hline \multicolumn{6}{|l|}{ Active population } \\
\hline Asbestos workers & 2056 & 21 & $2890(1789$ to 4417$)$ & 139 & $116(97$ to 136$)$ \\
\hline Potentially exposed workers & 385046 & 169 & $141(121$ to 164$)$ & 18097 & 88 (87 to 90$)$ \\
\hline All other workers & 1010597 & 249 & 68 (60 to 78$)$ & 53838 & 85 (84 to 86$)$ \\
\hline Missing information & 30922 & 12 & 103 (53 to 180$)$ & 2460 & $118(114$ to 123$)$ \\
\hline \multicolumn{6}{|l|}{ Non-active population } \\
\hline Pre-retirement & 190090 & 265 & 115 (101 to 130$)$ & 52575 & 108 (108 to 109$)$ \\
\hline Unemployed & 86131 & 45 & 130 (95 to 175$)$ & 9012 & 148 (145 to 151$)$ \\
\hline Disabled & 25046 & 25 & 140 (91 to 207$)$ & 6220 & 194 (189 to 198$)$ \\
\hline Students & 119742 & 0 & 0 (0 to 1678$)$ & 642 & 65 (59 to 69$)$ \\
\hline Other & 30734 & 2 & 59 (7 to 214$)$ & 1241 & $152(143$ to 160$)$ \\
\hline Missing information & 58938 & 14 & 71 (39 to 119$)$ & 4912 & 136 (132 to 139$)$ \\
\hline
\end{tabular}

${ }^{*}$ Reference population: Flemish and Brussels men (18-65 years).

$\mathrm{N}$, number of men; $\mathrm{O}$, observed number of deaths; SMR, standardised mortality ratio. 


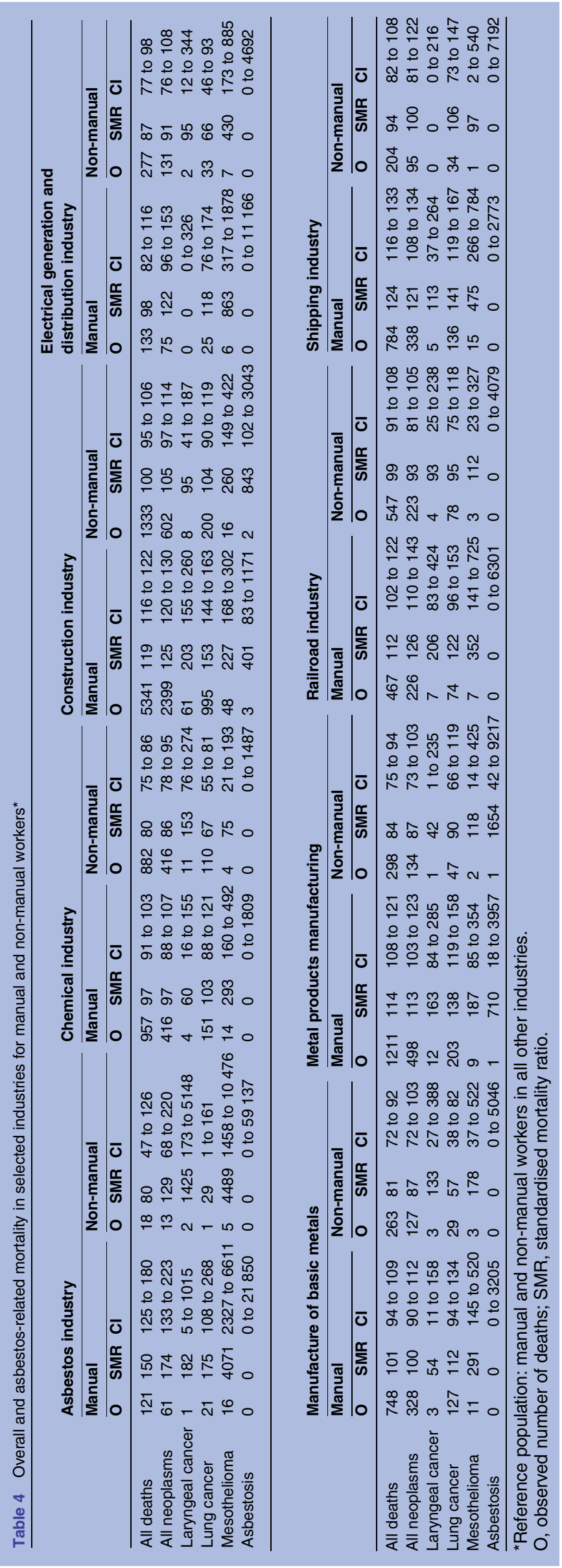

mouth cancer deaths than expected (SMR 140; CI 101 to 189). For construction workers, we also find significant excess in pharyngeal cancer mortality (SMR 151; CI 104 to 212 ).

Significant excess in mortality is found for two other types of malignancies. The SMR for oesophageal cancer mortality among construction workers in manual labour jobs equals 131 (CI 108 to 158). Prostate cancer deaths are two times higher among manual workers in shipping (SMR 203; CI 135 to 293).

Findings also indicate elevated mortality due to diseases of the circulatory system for manual workers in six industries: the asbestos industry, construction industry, basic metals manufacturing industry, metal products manufacturing industry, railroad industry and the shipping industry. Looking at the circulatory diseases separately, we find asbestos workers experience a higher number of deaths caused by cerebrovascular disease (SMR 200; CI 80 to 411) (not shown in table 5). Mortality due to ischaemic heart disease is significantly higher among construction workers (SMR 118; CI 109 to 127), shipping workers (SMR 124; CI 100 to 151) and railroad workers (SMR 132; CI 102 to 169) (not shown in table 5).

For mortality due to respiratory diseases, we find elevated SMRs for manual workers in the asbestos industry, construction industry, basic metals manufacturing industry, metal products manufacturing industry, railroad industry and the shipping industry. This is due to relatively high numbers of deaths from chronic obstructive pulmonary diseases (COPD). Mortality due to COPD is significantly higher for construction workers (SMR 127; CI 109 to 147), basic metals manufacturing workers (SMR 166; CI 116 to 230), metal products manufacturing workers (SMR 172; CI 128 to 226) and shipping industry workers (SMR 176; CI 124 to 243) (not shown in table 5). In addition to elevated mortality due to COPD (SMR 228; CI 84 to 496), results for asbestos workers indicate higher pneumonia mortality (SMR 336; CI 91 to 859) (not shown in table 5).

Construction workers in manual labour jobs experience excess mortality due to other diseases, because of a significantly higher number of deaths from alcoholic liver disease (SMR 138; CI 115 to 164, not shown in table 5).

\section{DISCUSSION}

Cause-specific mortality among high-risk workers and all other workers is compared to determine the current impact of asbestos exposure on Belgian workers' mortality. In addition to asbestos workers, 10 types of industrial workers are identified as potentially exposed. Results indicate significant excess in asbestos-related mortality in the asbestos industry and in seven of the selected industries, those being, the chemical industry, construction industry, electrical generation and distribution industry, basic metals manufacturing industry, metal products 
Table 5 Overall and cause-specific mortality in selected industries for manual and non-manual workers*

\begin{tabular}{|c|c|c|c|c|c|c|c|c|c|c|c|c|c|c|c|c|c|c|c|c|c|c|c|c|}
\hline & \multicolumn{6}{|c|}{ Asbestos industry } & \multicolumn{6}{|c|}{ Chemical industry } & \multicolumn{6}{|c|}{ Construction industry } & \multicolumn{6}{|c|}{$\begin{array}{l}\text { Electrical generation } \\
\text { and distribution industry }\end{array}$} \\
\hline & \multicolumn{3}{|c|}{ Manual } & \multicolumn{3}{|c|}{ Non-manual } & \multicolumn{3}{|c|}{ Manual } & \multicolumn{3}{|c|}{ Non-manual } & \multicolumn{3}{|c|}{ Manual } & \multicolumn{3}{|c|}{ Non-manual } & \multicolumn{3}{|c|}{ Manual } & \multicolumn{3}{|c|}{ Non-manual } \\
\hline & 0 & SMR & $\mathrm{Cl}$ & $\overline{0}$ & SMR & $\mathbf{C l}$ & $\overline{0}$ & SMR & Cl & 0 & SMR & $\mathrm{Cl}$ & 0 & SMR & $\mathbf{C l}$ & 0 & SMR & $\mathrm{Cl}$ & 0 & SMR & $\mathrm{Cl}$ & 0 & SMR & $\mathrm{Cl}$ \\
\hline All deaths & 121 & 150 & 125 to 180 & 18 & 80 & 47 to 126 & 957 & 97 & 91 to 103 & 882 & 80 & 75 to 86 & 5341 & 119 & 116 to 122 & 1333 & 100 & 95 to 106 & 133 & 398 & 82 to 116 & 277 & 787 & 77 to 98 \\
\hline All neoplasms & 61 & 174 & 133 to 223 & 13 & 129 & 68 to 220 & 416 & 97 & 88 to 107 & 416 & 86 & 78 to 95 & 2399 & 125 & 120 to 130 & 602 & 105 & 97 to 114 & 75 & 122 & 96 to 153 & 131 & 191 & 76 to 108 \\
\hline Malignant head and neck & 6 & 315 & 115 to 685 & 2 & 436 & 53 to 1576 & 19 & 82 & 50 to 129 & 18 & 74 & 44 to 117 & 155 & 148 & 126 to 173 & 32 & 114 & 78 to 160 & 2 & 64 & 8 to 233 & 6 & 86 & 32 to 187 \\
\hline Oral cancer & 5 & 383 & 124 to 894 & 0 & 0 & 0 to 985 & 15 & 95 & 53 to 157 & 7 & 43 & 17 to 88 & 89 & 125 & 100 to 153 & 22 & 116 & 73 to 176 & 2 & 95 & 12 to 344 & 4 & 86 & 23 to 219 \\
\hline Mouth & 5 & 938 & 305 to 2189 & 0 & 0 & 0 to 2351 & 5 & 77 & 25 to 180 & 3 & 44 & 9 to 129 & 42 & 140 & 101 to 189 & 9 & 114 & 52 to 216 & 0 & 0 & 0 to 352 & 1 & 52 & 1 to 287 \\
\hline Pharynx & 0 & 0 & 0 to 751 & 0 & 0 & 0 to 2993 & 3 & 62 & 13 to 181 & 4 & 73 & 20 to 187 & 33 & 151 & 104 to 212 & 7 & 110 & 44 to 227 & 1 & 164 & 4 to 912 & 2 & 128 & 15 to 462 \\
\hline Other head and neck & 0 & 0 & 0 to 5637 & 0 & 0 & 0 to 21873 & 0 & 0 & 0 to 469 & 0 & 0 & 0 to 431 & 5 & 168 & 55 to 393 & 2 & 244 & 30 to 883 & 0 & 0 & 0 to 3440 & 0 & 0 & 0 to 1516 \\
\hline Malignant digestive system & 7 & 76 & 31 to 157 & 1 & 38 & 1 to 209 & 110 & 98 & 80 to 118 & 119 & 94 & 78 to 112 & 561 & 111 & 102 to 121 & 140 & 93 & 78 to 109 & 17 & 105 & 61 to 169 & 36 & 95 & 67 to 132 \\
\hline Oesophageal cancer & 2 & 128 & 16 to 463 & 0 & 0 & 0 to 739 & 18 & 95 & 56 to 150 & 22 & 107 & 67 to 162 & 112 & 131 & 108 to 158 & 18 & 75 & 44 to 118 & 2 & 76 & 9 to 275 & 9 & 149 & 68 to 284 \\
\hline Stomach cancer & 1 & 84 & 2 to 471 & 0 & 0 & 0 to 899 & 17 & 117 & 68 to 188 & 10 & 63 & 30 to 115 & 77 & 118 & 93 to 148 & 24 & 127 & 81 to 189 & 4 & 197 & 54 to 504 & 1 & 21 & 1 to 118 \\
\hline Colon cancer & 1 & 38 & 1 to 214 & 0 & 0 & 0 to 380 & 33 & 104 & 71 to 146 & 32 & 87 & 59 to 123 & 152 & 106 & 90 to 125 & 33 & 75 & 51 to 105 & 2 & 43 & 5 to 156 & 13 & 118 & 63 to 202 \\
\hline Rectal cancer & 2 & 226 & 27 to 818 & 0 & 0 & 0 to 1168 & 13 & 121 & 64 to 206 & 12 & 99 & 51 to 173 & 58 & 121 & 92 to 157 & 19 & 133 & 80 to 208 & 3 & 192 & 40 to 562 & 2 & 55 & 7 to 197 \\
\hline Liver cancer & 0 & 0 & 0 to 290 & 0 & 0 & 0 to 984 & 9 & 72 & 33 to 136 & 14 & 98 & 54 to 165 & 53 & 94 & 70 to 123 & 13 & 77 & 41 to 131 & 2 & 109 & 13 to 393 & 3 & 70 & 14 to 203 \\
\hline Pancreas cancer & 1 & 54 & 1 to 298 & 1 & 183 & 5 to 1020 & 18 & 79 & 47 to 125 & 28 & 108 & 72 to 156 & 101 & 99 & 80 to 120 & 31 & 100 & 68 to 142 & 4 & 122 & 33 to 312 & 8 & 104 & 45 to 204 \\
\hline Other digestive & 0 & 0 & 0 to 3427 & 0 & 0 & 0 to 10249 & 2 & 186 & 23 to 673 & 1 & 72 & 2 to 402 & 8 & 160 & 69 to 314 & 2 & 114 & 14 to 411 & 0 & 0 & 0 to 1864 & 0 & 0 & 0 to 763 \\
\hline Malignant urogenital system & 6 & 159 & 58 to 346 & 2 & 163 & 20 to 590 & 38 & 82 & 58 to 113 & 48 & 86 & 63 to 113 & 216 & 103 & 90 to 118 & 65 & 94 & 73 to 120 & 10 & 144 & 69 to 264 & 19 & 113 & 68 to 177 \\
\hline Prostate cancer & 3 & 175 & 36 to 511 & 0 & 0 & 0 to 498 & 18 & 85 & 51 to 135 & 27 & 99 & 66 to 145 & 98 & 101 & 82 to 123 & 28 & 82 & 55 to 119 & 5 & 153 & 50 to 357 & 8 & 100 & 43 to 196 \\
\hline Testicular cancer & 0 & 0 & 0 to 13840 & 0 & 0 & 0 to 92164 & 0 & 0 & 0 to 1140 & 0 & 0 & 0 to 1726 & 3 & 203 & 42 to 594 & 2 & 683 & 83 to 2469 & 0 & 0 & 0 to 13444 & 40 & 0 & 0 to 7289 \\
\hline Bladder cancer & 1 & 103 & 3 to 573 & 1 & 322 & 8 to 1792 & 10 & 85 & 41 to 156 & 10 & 70 & 34 to 129 & 64 & 120 & 92 to 153 & 17 & 99 & 57 to 158 & 2 & 111 & 13 to 402 & 4 & 92 & 25 to 237 \\
\hline Kidney cancer & 2 & 188 & 23 to 680 & 1 & 324 & 8 to 1806 & 10 & 77 & 37 to 142 & 11 & 76 & 38 to 135 & 51 & 88 & 66 to 116 & 18 & 105 & 62 to 166 & 3 & 160 & 33 to 468 & 7 & 160 & 64 to 329 \\
\hline Non-neoplasms & 48 & 130 & 96 to 173 & 4 & 36 & 10 to 93 & 430 & 95 & 86 to 105 & 401 & 76 & 69 to 84 & 2313 & 112 & 107 to 116 & 607 & 94 & 87 to 102 & 51 & 80 & 59 to 105 & 127 & 784 & 70 to 100 \\
\hline Circulatory system & 27 & 131 & 86 to 191 & 2 & 32 & 4 to 117 & 238 & 94 & 83 to 107 & 230 & 78 & 68 to 89 & 1298 & 113 & 107 to 119 & 360 & 100 & 90 to 110 & 31 & 86 & 58 to 122 & 74 & 87 & 68 to 109 \\
\hline Respiratory system & 10 & 238 & 114 to 437 & 1 & 70 & 2 to 391 & 46 & 89 & 65 to 119 & 36 & 56 & 39 to 77 & 279 & 118 & 104 to 132 & 74 & 91 & 72 to 114 & 4 & 51 & 14 to 131 & 18 & 95 & 56 to 150 \\
\hline Other diseases & 11 & 91 & 46 to 163 & 1 & 30 & 1 to 166 & 146 & 99 & 83 to 116 & 135 & 81 & 68 to 96 & 736 & 108 & 101 to 116 & 173 & 85 & 73 to 99 & 16 & 80 & 45 to 129 & 35 & 75 & 52 to 104 \\
\hline \multirow{4}{*}{ External code } & 12 & 141 & 73 to 247 & 1 & 64 & 2 to 357 & 111 & 104 & 86 to 125 & 65 & 71 & 55 to 91 & 629 & 127 & 118 to 138 & 124 & 111 & 93 to 133 & 7 & 66 & 27 to 137 & 19 & 87 & 52 to 135 \\
\hline & \multicolumn{6}{|c|}{ Manufacture of basic metals } & \multicolumn{6}{|c|}{ Metal products manufacturing } & \multicolumn{6}{|c|}{ Railroad industry } & Ship & ping in & ndustry & & & \\
\hline & Mant & & & Non- & 1-manc & & Manu & & & Non & n-mant & iual & Man & nual & & Non & i-manue & & $\overline{M a n u}$ & & & Non-r & -manua & \\
\hline & $\overline{0}$ & SMR & $\mathrm{Cl}$ & $\overline{0}$ & SMR & $\mathrm{Cl}$ & 0 & SMR & $\mathrm{Cl}$ & $\overline{0}$ & SMR & $\mathrm{R} \mathrm{Cl}$ & $\overline{0}$ & SMR & $\mathrm{Cl}$ & $\overline{0}$ & SMR & $\mathrm{Cl}$ & 0 & SMR & $\mathrm{Cl}$ & $\overline{0}$ & SMR & $\mathbf{C l}$ \\
\hline All dea & 748 & 101 & 9 & 263 & 81 & 7 & 1211 & 114 & 108 & 1298 & 884 & 75 to 94 & 467 & 112 & 122 & 547 & 9 & 08 & 784 & 124 & 133 & 204 & 94 & \\
\hline All neoplasms & 328 & 100 & 90 to 112 & 127 & 87 & 72 to 103 & 498 & 113 & 103 to 123 & 3134 & 487 & 73 to 103 & 3226 & 126 & 110 to 143 & 3223 & 93 & 81 to 105 & 338 & 121 & 108 to 134 & 95 & 100 & 81 to 122 \\
\hline Malignant head and neck & 9 & 46 & 21 to 87 & 8 & 104 & 45 to 206 & 37 & 141 & 99 to 194 & 3 & 37 & 8 to 109 & 25 & 199 & 128 to 293 & 316 & 102 & 59 to 166 & 23 & 150 & 95 to 225 & 2 & 43 & 5 to 156 \\
\hline Oral cancer & 6 & 44 & 16 to 96 & 5 & 96 & 31 to 225 & 24 & 132 & 85 to 196 & 2 & 37 & 4 to 132 & 17 & 192 & 112 to 308 & 312 & 110 & 57 to 192 & 18 & 172 & 102 to 271 & 1 & 32 & 1 to 179 \\
\hline Mouth & 3 & 54 & 11 to 158 & 3 & 139 & 29 to 407 & 11 & 148 & 74 to 264 & 2 & 88 & 11 to 317 & 714 & 390 & 213 to 655 & 55 & 111 & 36 to 258 & 9 & 211 & 96 to 400 & 1 & 77 & 2 to 429 \\
\hline Pharynx & 2 & 51 & 6 to 184 & 1 & 57 & 1 to 317 & 9 & 155 & 71 to 295 & 0 & 0 & 0 to 162 & 2 & 71 & 9 to 255 & 1 & 27 & 1 to 150 & 5 & 157 & 51 to 367 & 0 & 0 & 0 to 288 \\
\hline Other hea & 0 & 0 & 0 to 588 & 0 & 0 & 0 to 1410 & 1 & 137 & 3 to 766 & 0 & 0 & 0 to 1302 & 21 & 285 & 7 to 1589 & 0 & 0 & 0 to 700 & 0 & 0 & 0 to 706 & 1 & 741 & 19 to 4131 \\
\hline estive system & 87 & 102 & 81 to 125 & 39 & 101 & 72 to 138 & 100 & 87 & 71 to 106 & 40 & 99 & 70 to 134 & 446 & 98 & 72 to 131 & 58 & 92 & 70 to 119 & 74 & 101 & 79 to 126 & 19 & 76 & 46 to 119 \\
\hline Oesophageal cancer & 16 & 103 & 59 to 168 & 5 & 78 & 25 to 183 & 22 & 107 & 67 to 162 & 5 & 74 & 24 to 174 & 410 & 106 & 51 to 196 & 11 & 91 & 45 to 163 & 14 & 112 & 61 to 187 & 2 & 50 & 6 to 181 \\
\hline Stomach cancer & 12 & 109 & 56 to 191 & 3 & 62 & 13 to 182 & 22 & 145 & 91 to 220 & 4 & 78 & 21 to 201 & 16 & 98 & 36 to 213 & 5 & 61 & 20 to 143 & 12 & 128 & 66 to 223 & 3 & 96 & 20 to 280 \\
\hline
\end{tabular}

Continued 


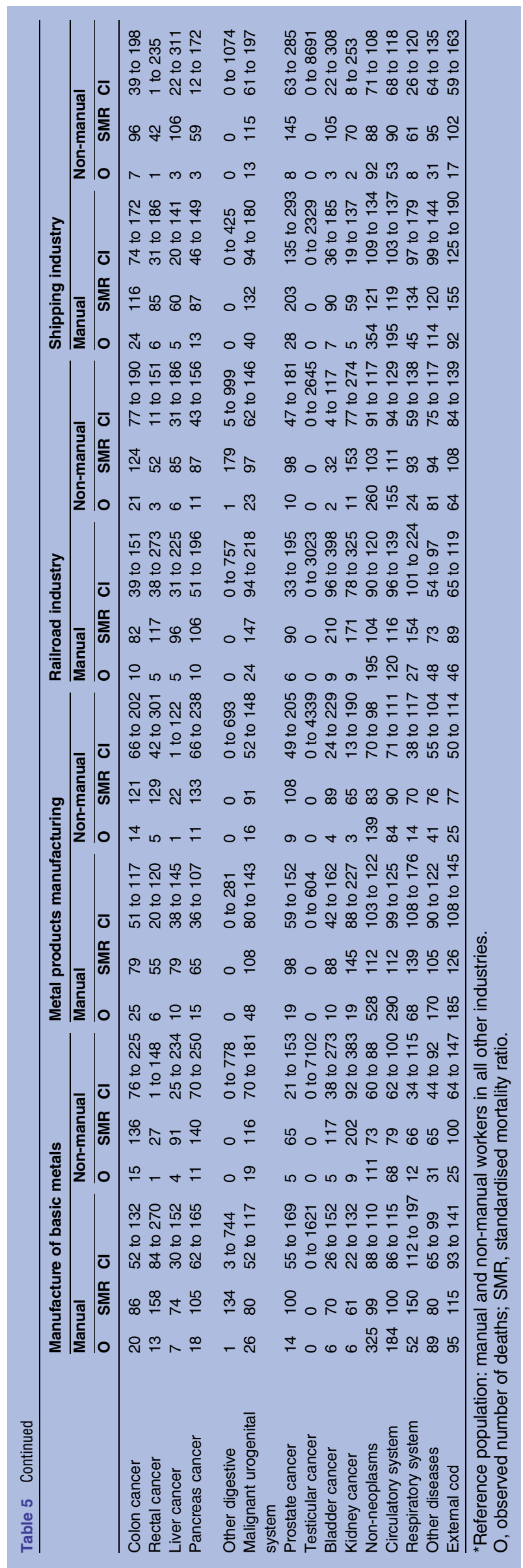

manufacturing industry, railroad industry and the shipping industry. Contrary to other reports, ${ }^{15-21}$ we did not find significant excess risks for asbestos-related mortality in the automotive industry, textile industry or in the electrotechnical industry.

Results clearly show a very high impact of asbestos exposure on asbestos workers. Mesothelioma mortality is 41 times higher among manual workers and 45 times higher among non-manual workers than in the reference population. Significant excess in laryngeal cancer and lung cancer mortality is found for non-manual workers and manual workers, respectively. Working in the asbestos industry seems to entail serious asbestosrelated health risks, regardless of the occupational type. It is likely that asbestos exposure in this industry is not confined to specific work-related tasks, but also includes site-related environmental exposure.

Among potentially exposed workers, significant excess in mesothelioma mortality is found for manual work in the chemical industry, the basic metal manufacturing industry and the railroad industry. Surprisingly, manual and non-manual workers in the electricity generation and distribution industry both have a significantly higher number of mesothelioma deaths. This may indicate more widespread asbestos exposure in this industry than expected.

Shipping industry workers in manual labour jobs experience significantly higher mesothelioma and lung cancer mortality. Results also show increased mortality risks for mesothelioma and lung cancer among manual workers in metal products manufacturing, with significant excess in lung cancer deaths.

The construction industry is the only industry with elevated SMRs for all four established asbestos-related diseases. In addition to manual workers, non-manual workers in the construction industry experience significantly higher numbers of mesothelioma and asbestosis deaths. An underestimation of asbestosis mortality is possible because asbestosis is frequently coded as a contributing cause of death, and this study is based on underlying causes of death.

Cause-specific mortality is further scrutinised to identify additional excess in mortality among high-risk workers and evaluate a potential association with asbestos exposure. The results for four industries corroborate a possible association between asbestos exposure and the development of oral cancer. Manual workers in the asbestos industry, construction industry, shipping industry and the railroad industry have significantly higher oral cancer mortality. Tobacco and alcohol consumption are considered to be major risk factors. ${ }^{22}$ However, occupational asbestos exposure has also been reported as a possible causal factor for oral cancer types, ${ }^{23-25}$ and for pharyngeal cancer. ${ }^{26}$ Historical exposure circumstances should be explored further in order to answer why, specifically, these workers experience high oral cancer mortality.

Reports of elevated prostate cancer risks related to occupational asbestos exposure are scarce. ${ }^{27} 28$ 
Krstev et a $t^{29}$ found significant excess prostate cancer mortality among unexposed shipping workers. Therefore, a causal effect of asbestos exposure is doubtful.

Potential confounding factors for laryngeal cancer are smoking and alcohol use. Tobacco consumption, a major risk factor for lung cancer, could even have a multiplicative effect when combined with asbestos. ${ }^{30} 31$ Considering the use of various carcinogens such as nickel, cadmium or PAHs in the selected industries, concomitant occupational exposure is highly likely. Because of insufficient data, potential confounders could not be considered in our analyses. Results do show that manual workers in construction, in basic metal manufacturing, in metal products manufacturing and in shipping, have significantly higher mortality due to COPD, which is known to be caused predominantly by smoking. Occupational exposure to dust, fumes and gases has been associated with increased incidence of COPD. ${ }^{32}$ Construction workers also experience significant excess in mortality due to alcoholic liver disease, oesophageal cancer, mouth cancer and pharyngeal cancer, suggesting high alcohol use. Although mesothelioma and asbestosis mortality provides clear indications of considerable asbestos-related health effects in these industries, further research is needed to estimate the effect of asbestos exposure on lung cancer and laryngeal cancer mortality.

The main advantage of this study is the availability of census-linked, cause-specific mortality data. The anonymous linkage at the individual level minimises the nominator-denominator bias. Furthermore, even industries with relatively small working populations could be included in this study, due to the large number of persons in the data set.

The study design has some limitations. Occupational information is only available for a specific time period. Our findings may be confounded by exposure during previous jobs. Persons who have already quit asbestos-related industries at the time of the 1991 census cannot be identified. The most heavily exposed workers may have already left the workforce due to health reasons. As only actively employed workers are studied, healthy worker effects may bias our results. Based on the number of mesothelioma deaths among pre-retired men in the non-active population, we believe that a considerable proportion of occupational asbestos victims remain unnoticed.

As a result of job changes prior to the census date, it is also possible that occupationally exposed workers are included in the reference population. Although workers in the reference population are at least partially exposed to asbestos in the environment or through indirect contact, the number of mesothelioma deaths is larger than anticipated. As recent studies estimate that $8.3 \%$ to $11 \%$ of all mesothelioma deaths are attributable to non-occupational asbestos exposure, ${ }^{33} 34$ our results may still underestimate the true influence of occupational asbestos exposure.

Occupational information after the 1991 census is not available. Hence, potential confounders related to the last job have not been taken into account. Owing to the long period between asbestos exposure and onset of related diseases, we believe this does not alter the interpretation of our results.

Assumptions on asbestos exposure are industry-based. Although occupational type is considered, individual exposure information is not available and the number of workers at risk is surely overestimated. It is possible that asbestos exposure occurs in some industries only among specific groups of workers at specific workstations, and the effect of occupational asbestos exposure remains unnoticed. This may explain why no significant effects were found for asbestos-related mortality in the automotive industry, the textile industry and the electrotechnical industry.

The distinction between manual and non-manual workers is based on the physical or intellectual nature of the work, as stated in the labour agreement between employer and employee. This criterion is highly subject to interpretation. Reports have been made of workers doing the same job, but with different statuses (bluecollar vs white-collar status). ${ }^{35} 36$

In conclusion, cause-specific mortality reveals the repercussions of historical asbestos use on Belgian workers. Asbestos workers are not the only employees to experience increased asbestos-related mortality. The study also identifies eight industries with significantly elevated asbestos-related mortality, which have been previously overlooked in Belgian asbestos research. Furthermore, observations in four industries indicate a possible association between occupational asbestos exposure and the development of oral cancer. This study contributes to the large amount of international evidence on the adverse health effects of occupational asbestos exposure. Workers should be informed about the risks of past exposure and all forms of asbestos use should be banned.

Acknowledgements The authors thank Didier Willaert for his much-appreciated help in preparing the data and Jan De Schampheleire for his expert advice on the Belgian labour market.

Contributors PD and LVdB designed the study. LVdB conducted the study and wrote the first draft of the manuscript. Both authors edited the draft, discussed the interpretation and approved the final version of the manuscript.

Funding The Research Council of Vrije Universiteit Brussel supported the study. LVdB is a PhD fellow at the Research Foundation-Flanders (FWO). Preliminary results were presented at the 2014 European Population Conference and the XX World Congress on Safety and Health at Work.

Competing interests None declared.

Ethics approval The Belgian Commission for the protection of privacy.

Provenance and peer review Not commissioned; externally peer reviewed.

Data sharing statement Analyses are based on administrative data from the Belgian Census, the Belgian mortality register and death certificates provided by Statistics Belgium. The availability of the data is restricted. Permission for analyses must be granted after verification of the research goals by the Belgian Commission for the protection of privacy.

Open Access This is an Open Access article distributed in accordance with the Creative Commons Attribution Non Commercial (CC BY-NC 4.0) license, which permits others to distribute, remix, adapt, build upon this work noncommercially, and license their derivative works on different terms, provided the original work is properly cited and the use is non-commercial. See: http:// creativecommons.org/licenses/by-nc/4.0/ 


\section{REFERENCES}

1. Van den Borre L, Deboosere P. Asbestos in Belgium: an underestimated health risk. The evolution of mesothelioma mortality rates (1969-2009). Int J Occup Environ Health 2014;20: 134-40.

2. Weill $\mathrm{H}$, Hughes $\mathrm{J}$, Churg A. Changing trends in US mesothelioma incidence. Occup Environ Med 2004;61:438-41.

3. Virta RL. Worldwide asbestos supply and consumption trends from 1900 through 2003. Reston, VA: U.S. Department of the Interior; 2006, U.S. Geological Survey Report No.: Circular 1298.

4. Vande Weyer R. Bilan de l'indemnisation de l'asbestose. Acta Tuberc Pneumol Belg 1973;64:304-51.

5. Lacquet LM, van der Linden L, Lepoutre J. Roentgenographic lung changes, asbestosis and mortality in a Belgian asbestos-cement factory. In: Wagner JC, ed. Biological effects of mineral fibres IARC Scientific Publication 30. Lyon, France: International Agency for Research on Cancer, 1980:783-95.

6. Nawrot T, Van Kersschaever G, Van Eycken E, et al. Belgium: historical champion in asbestos consumption. Lancet 2007;369:1692

7. De Kezel E. Asbest, gezondheid en veiligheid. Ontwikkelingen in het aansprakelijkheidsrecht. Antwerpen: Intersentia, 2013.

8. Nay SY. Asbestos in Belgium: use and abuse. Int $J$ Occup Environ Health 2003;9:287-93.

9. Van De Voorde H, Meulepas E, Gyselen A, et al. Doodsoorzaken bi de bevolking woonachtig rond en bij de arbeiders werkzaam in een asbestverwerkende nijverheid in het noorden van Brabant. Acta Tuberc Pneumol Belg 1967;58:924-42.

10. Vande Weyer R. Pathologie respiratoire de l'amiante en Belgique. Rev Méd Brux 1981;2:69-81.

11. International Agency for Research on Cancer. Asbestos (chrysotile, amosite, crocidolite, tremolite, actinolite, and anthophyllite). A review of human carcinogens Part $C$ : Arsenic, metals, fibres, and dusts/ IARC Working Group on the Evaluation of Carcinogenic Risks to Humans. Vol. 100. Lyon, France: International Agency for Research on Cancer, 2012:219-309.

12. Scientific Institute of Public Health, Public Health and Surveillance. Standardized procedures for mortality analysis. Brussels, 2015. http s://www.wiv-isp.be/epidemio/spma

13. Hillerdal G. Mesothelioma: cases associated with non-occupational and low dose exposures. Occup Environ Med 1999;56:505-13. http://oem.bmj.com/cgi/doi/10.1136/oem.56.8.505

14. Rothman KJ, Boice JD. Epidemiological analysis with a programmable calculator. Washington DC: US Government Printing Office, 1979.

15. Paustenbach DJ, Madl AK, Donovan E, et al. Chrysotile asbestos exposure associated with removal of automobile exhaust systems (ca. 1945-1975) by mechanics: results of a simulation study. J Expo Sci Environ Epidemiol 2006;16:156-71.

16. Finkelstein MM. Asbestos fibre concentrations in the lungs of brake workers: another look. Ann Occup Hyg 2008; 52:455-61.

17. Ameille J, Rosenberg N, Matrat M, et al. Asbestos-related diseases in automobile mechanics. Ann Occup Hyg 2012;56: 55-60.

18. Lin S, Wang X, Yu ITS, et al. Cause-specific mortality in relation to chrysotile-asbestos exposure in a Chinese cohort. $J$ Thorac Oncol 2012;7:1109-14.
19. Pira E, Pelucchi C, Piolatto PG, et al. First and subsequent asbestos exposures in relation to mesothelioma and lung cancer mortality. Br J Cancer 2007;97:1300-4.

20. Hein MJ, Stayner LT, Lehman E, et al. Follow-up study of chrysotile textile workers: cohort mortality and exposure-response. Occup Environ Med 2007;64:616-25.

21. Fear NT, Roman E, Carpenter LM, et al. Cancer in electrical workers: an analysis of cancer registrations in England, 1981-87. Br J Cancer 1996;73:935-9.

22. Hashibe M, Brennan $\mathrm{P}$, Chuang $\mathrm{S}$, et al. Interaction between tobacco and alcohol use and the risk of head and neck cancer: pooled analysis in the INHANCE Consortium. Cancer Epidemiol Biomarkers Prev 2009;18:541-50.

23. Paget-Bailly S, Cyr D, Luce D. Occupational exposures to asbestos, polycyclic aromatic hydrocarbons and solvents, and cancers of the oral cavity and pharynx: a quantitative literature review. Int Arch Occup Environ Health 2012;85:341-51.

24. Dement J, Welch L, Haile E, et al. Mortality among sheet metal workers participating in a medical screening program. Am J Ind Med 2009;52:603-13.

25. Ulvestad B, Kjærheim K, Martinsen JI, et al. Cancer incidence among workers in the asbestos-cement producing industry in Norway. Scand J Work Environ Health 2002;28:411-17.

26. Langevin SM, O'Sullivan $\mathrm{MH}$, Valerio $\mathrm{JL}$, et al. Occupational asbestos exposure is associated with pharyngeal squamous cell carcinoma in men from the greater Boston area. Occup Environ Med 2013;70:858-63.

27. Koskinen K, Pukkala E, Reijula K, et al. Incidence of cancer among the participants of the Finnish Asbestos Screening Campaign. Scand J Work Environ Health 2003;29:64-70.

28. Raffn E, Lynge E, Juel K, et al. Incidence of cancer and mortality among employees in the asbestos cement industry in Denmark. $\mathrm{Br} J$ Ind Med 1989;46:90-6.

29. Krstev S, Stewart P, Rusiecki J, et al. Mortality among shipyard Coast Guard workers: a retrospective cohort study. Occup Environ Med 2007;64:651-8.

30. Gustavsson P. Low-dose exposure to asbestos and lung cancer: dose-response relations and interaction with smoking in a population-based case-referent study in Stockholm, Sweden. Am J Epidemiol 2002;155:1016-22.

31. Markowitz SB, Levin SM, Miller A, et al. Asbestos, asbestosis, smoking, and lung cancer. New findings from the North American insulator cohort. Am J Respir Crit Care Med 2013;188:90-6.

32. Blanc PD, Iribarren C, Trupin L, et al. Occupational exposures and the risk of COPD: dusty trades revisited. Thorax 2009;64:6-12.

33. Boffetta P, McLaughlin JK, la Vecchia C, et al. "Environment" in cancer causation and etiological fraction: limitations and ambiguities. Carcinogenesis 2007;28:913-15.

34. Mirabelli D, Cavone D, Merler E, et al. Non-occupational exposure to asbestos and malignant mesothelioma in the Italian National Registry of Mesotheliomas. Occup Environ Med 2010;67:792-4.

35. Starr P. Social categories and claims in the liberal state. In: Douglas M, Hull D, eds. How classification works. Edinburgh University Press, 1992:154-79.

36. Pichault F, Xhauflair V, Deflandre D, et al. Flexibiliteit en Aantrekkelijkheid: Sociaal overleg in een context van projectmanagement. Report Federatie van Algemene Bouwondernemers-Fédération des Entrepreneurs Généraux de la Construction, 2005:103. 